\title{
STRUCTURE OF Co(III) AND Fe(III) TRANSITION METAL IONS IN AQUEOUS
} SOLUTION

\author{
Ahmed M. Mohammed* \\ Department of Chemistry, Addis Ababa University, P.O. Box. 1176, Addis Ababa, Ethiopia
}

(Received May 26, 2005; revised July 22, 2005)

\begin{abstract}
The hydration structures of $\mathrm{Co}(\mathrm{III})$ and $\mathrm{Fe}(\mathrm{III})$ ions have been investigated by Metropolis Monte Carlo (MC) simulations using only ion-water pair interaction potentials and by including up to three body correction terms. The hydration structures were evaluated in terms of radial distribution functions, coordination numbers and angular distributions. The structural parameters obtained by including three-body correction terms are in good agreement with experimental values proving that many-body effects play a crucial role in the description of the hydration structure of these highly charged ions.
\end{abstract}

KEY WORDS: Metropolis Monte Carlo simulation, Hydration structure, Fe(III) and Co(III) ions, Three-body corrections

\section{INTRODUCTION}

Due to their fundamental importance in many chemical and biological processes aqueous solvation of metal ions have been investigated by various experimental techniques [1-11] and computer simulations [8, 12-23]. However, experimental determinations of a detailed microscopic solvation structure quickly reach their limits. In addition, serious problems arise due to the fact that high concentrations of salts have to be used in most diffraction studies [1, 2, 24]. At high concentrations, the solvation structure becomes increasingly perturbed by direct interaction with counterions. Classical computer simulations, both of Monte Carlo (MC) and molecular dynamics (MD) type, using ab initio potential energy functions have proven to be an increasingly useful tool for studying the solvation structure of ions [16-21, 23]. Their success, however, strongly depends on the quality of the potentials used to describe the interaction between the particles in the model system [25]. The most common potentials being used to describe ion-solvent interactions are based on the assumption of pairwise additivity, which, however, suffers a major problem, i.e., overestimation of the total binding energy, which resulting from the neglect of mutual polarization [26]. This problem which affects both structural and energetic data [19] has been widely examined for polar systems such as water [23, 27], and becomes much more serious in the case of interactions between ions and polar molecules, particularly highly charged ions [28]. Various approaches have been used to handle the failure of pairwise additivity of ion-water potential [29]. The most straightforward approach is to supplement the pair potential energy function by many-body terms. In many cases, threebody potentials that are calculated by ab initio methods have reproduced structural parameters properly [18-20, 30].

Solvation of singly and doubly charged metal ions has been studied extensively [8, 21, 24, 31-37], but significantly less information is available for trivalent transition metal ions; these ions have a similar importance in many chemical and biological processes. In order to understand these processes, it is desirable to know more about the micro-species formed by these metal ions in aqueous solutions. $\mathrm{Fe}^{3+}$ ion is stable in solution and only mildly oxidizing, while $\mathrm{Co}(\mathrm{III})$ ion, is a strong oxidant, rather instable in aqueous solution. Its structure has been studied

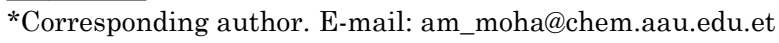


therefore, mostly in the solid state [37]. $\mathrm{Co}\left(\mathrm{H}_{2} \mathrm{O}\right)_{6}{ }^{3+}$ ion is well characterized in alums [38-39] and in the hydrated sulfate $\mathrm{Co}_{2}\left(\mathrm{SO}_{4}\right)_{3} \cdot 18 \mathrm{H}_{2} \mathrm{O}$ [40]. Solutions containing the $\mathrm{Fe}(\mathrm{II})-\mathrm{Fe}(\mathrm{III})$ redox system exhibit a rich variety of chemical and biological potency [41]. As a result, they have been the subjects of numerous experimental [42] and theoretical investigations. The study of Fe(III) hydration has particularly attracted attention [43], and the hexoaquo Fe(III) complex has been observed in solution by both experimental [42] and theoretical methods [43].

In this work, $\mathrm{MC}$ simulations with and without 3-body corrections for one $\mathrm{M}(\mathrm{III})(\mathrm{M}=\mathrm{Co}$, $\mathrm{Fe}$ ) in 499 water molecules were performed, corresponding to a dilute ionic solution. The structural data of the hydrated $\mathrm{M}(\mathrm{III})$ ions are discussed in terms of $\mathrm{M}(\mathrm{III})-\mathrm{O}$ and $\mathrm{M}(\mathrm{III})-\mathrm{H}$ radial distribution functions (RDFs), coordination number and angular distributions.

\section{DETAILS OF CALCULATIONS}

In this study, the ion-water ( $\mathrm{M}(\mathrm{III})-\mathrm{H}_{2} \mathrm{O}, \mathrm{M}=\mathrm{Co}, \mathrm{Fe}$ ) pair interaction potentials and three-body corrections $\left(\mathrm{H}_{2} \mathrm{O}-\mathrm{M}(\mathrm{III})-\mathrm{H}_{2} \mathrm{O}\right)$ are taken from reference $44 \mathrm{a}$ for $\mathrm{Fe}(\mathrm{III})$ and $44 \mathrm{~b}$ for $\mathrm{Co}(\mathrm{III})$, the form of the potentials together with their parameters are displayed in Table 1. For water-water interactions, the CF2 potential [45] was used, as this model is more consistent than the MCY [46] model for the type of ion-water pair potentials used [47] and in contrast to rigid models [40] (TIP3P, TIP4P and TIP5P) allows an adaptation of $\mathrm{HOH}$ angle and $\mathrm{OH}$ bond length in the ligand molecules upon complexing the metal ion.

Table 1. Parameters for two-body and three-body correction functions of $\mathrm{M}(\mathrm{III})$-water $(\mathrm{M}=\mathrm{Co}$ and $\mathrm{Fe})$ interactions.

\begin{tabular}{|c|c|c|c|c|c|c|}
\hline \multicolumn{7}{|c|}{ 2-body } \\
\hline \multicolumn{2}{|c|}{$E_{2 h d}=\sum$} & $=\sum_{i}\left(\frac{q_{i} q_{M}}{r_{i M}}+\right.$ & \multicolumn{3}{|c|}{$\left(\underline{q_{i} q_{M}}+A_{M} r_{M}^{-A}+B_{M} r^{-B}+C^{-B} r_{M}^{-C}+D_{M} r_{M}^{-D}\right)$} & \\
\hline \multirow[t]{2}{*}{$\mathrm{M}(\mathrm{III})$} & Atom & $\mathrm{A}(\mathrm{kcal} / \mathrm{mol})$ & $\mathrm{B}(\mathrm{kcal} / \mathrm{mol})$ & $\mathrm{C}(\mathrm{kcal} / \mathrm{mol})$ & $\mathrm{D}(\mathrm{kcal} / \mathrm{mol})$ & $A, B, C, D$ \\
\hline & $\mathrm{O}$ & 11456.50 & 81418.48 & 86802.12 & 23768.78 & $5,7,9,12$ \\
\hline \multirow[t]{2}{*}{$\mathrm{Fe}$} & $\mathrm{H}$ & 818.31 & 2434.12 & 1098.57 & 1333.07 & $5,7,9,12$ \\
\hline & $\mathrm{O}$ & 7937.72 & 126798.37 & 167197.13 & 60178.06 & $5,6,9,12$ \\
\hline $\mathrm{Co}$ & $\mathrm{H}$ & 632.27 & 3542.28 & 3102.93 & 115.887 & $5,6,9,12$ \\
\hline \multicolumn{7}{|c|}{ 3-body } \\
\hline \multicolumn{7}{|c|}{$E_{3 b d}=\left(A_{1} \exp \left(-A_{2}\left({r_{M O_{1}}}^{2}+{r_{M O_{2}}}^{2}\right)\right) \exp \left(-A_{3}\left(r_{O_{1} O_{2}}\right)\right)^{2}-\frac{A_{4}}{r_{M O_{1}}}-\frac{A_{4}}{r_{M O_{2}}}\right.$} \\
\hline $\mathrm{H}_{2} \mathrm{O}-$ & (III) $-\mathrm{H}_{2} \mathrm{O}$ & $A_{I}$ & $A_{2}$ & $A_{3}$ & $A_{4}$ & $A_{5}$ \\
\hline & $\mathrm{Fe}$ & 59.5398695 & 0.4485195 & 2.1955235 & 0.0171252 & 0.0337411 \\
\hline & $\mathrm{Co}$ & 0.6560400 & 0.3284183 & 0.4201692 & - & - \\
\hline
\end{tabular}

Charges on $\mathrm{O}$ and $\mathrm{H}$, taken from the CF2 [45] water-water interaction potential, are -0.6598 and 0.3299 , respectively. $\mathrm{M}$ and $\mathrm{i}$ in the 2-body potential refer to metal ion and oxygen or hydrogen, respectively. $\mathrm{O}_{\mathrm{i}}$ and $\mathrm{CL}$ in the 3-body potential refer to the oxygens of the water molecules and cut off limit $(6 \AA)$, respectively.

The pair potentials were constructed by placing the $\mathrm{M}(\mathrm{III})$ ion at numerous positions around the water molecule and varying geometrical parameters $0^{\circ} \leq \Theta \leq 180^{\circ}$ and $0^{\circ} \leq \varphi \leq 90^{\circ}$; for each configuration and the M-O internuclear distance $r$ from 1.2 to $15.0 \AA$, Figure 1 . 


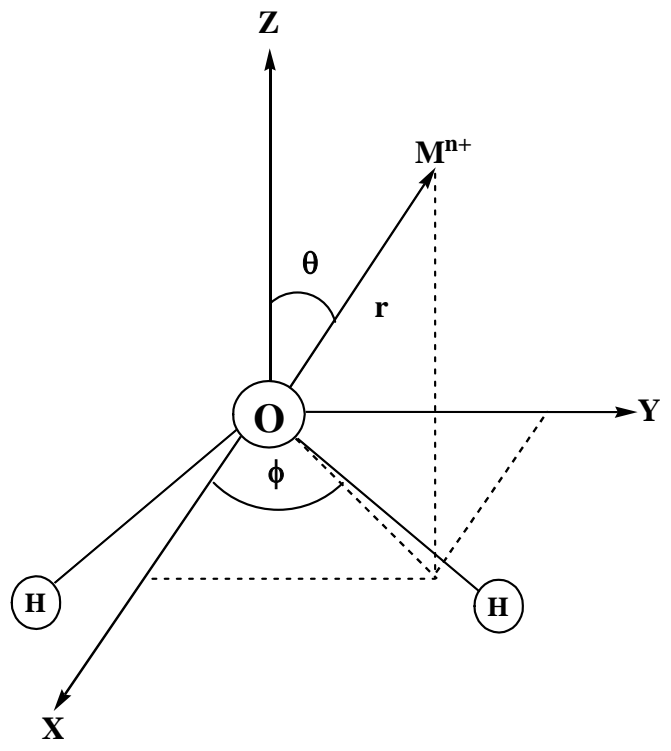

Figure 1. Definition of geometric variables $\mathrm{M}(\mathrm{III})-\mathrm{H}_{2} \mathrm{O}$ orientations. $\mathrm{H}_{2} \mathrm{O}$ molecules in yz plane.

Whereas the three body correction terms were generated starting from the equilibrium geometry $\left(\phi=180^{\circ}\right)$ and independently varying both $\mathrm{M}(\mathrm{III})-\mathrm{O}$ distances $\mathrm{r}_{1}$ and $\mathrm{r}_{2}$, the O-O distance $\mathrm{r}_{3}$, and the torsional angle $\tau$ as shown in Figure 2. The internal geometric parameters of water were held fixed at the CF2 values [45].

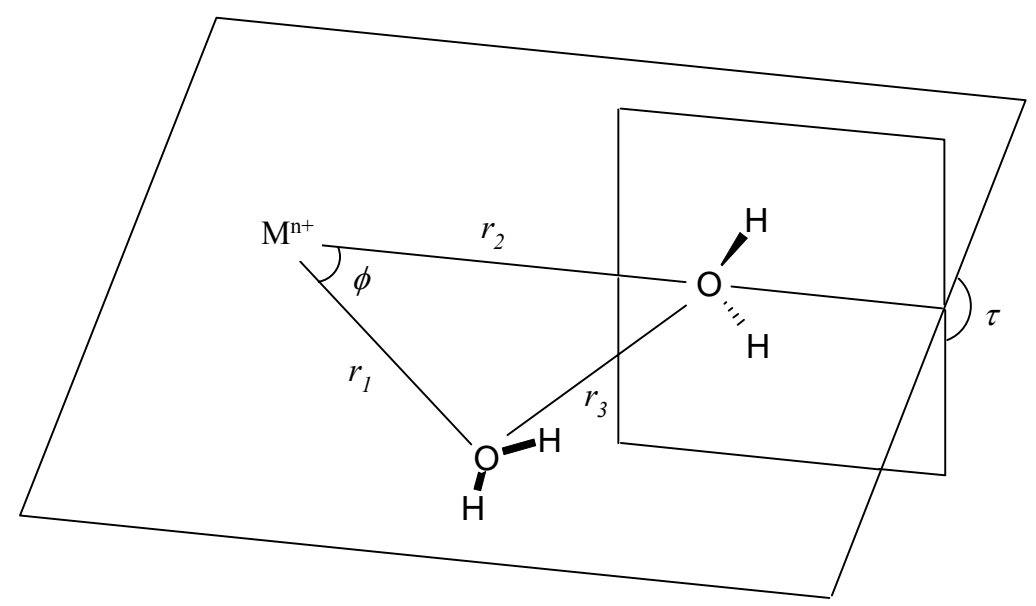

Figure 2. Geometrical variations in SCF calculations on the $\mathrm{H}_{2} \mathrm{O}-\mathrm{M}(\mathrm{III})-\mathrm{H}_{2} \mathrm{O}$ energy surface. 
MC simulations with pair potential

The MC simulations were carried out in the canonical ensemble using the Metropolis [48] algorithm for a system consisting of one M(III) ion and 499 water molecules in a periodic cube at the temperature $298.16 \mathrm{~K}$. A spherical cutoff at half of the box length $(12.345 \AA)$ was introduced. The density of $0.997 \mathrm{~g} \mathrm{~cm}^{-3}$ was assumed to be the same as that of pure water. After generating a starting configuration randomly, the system reached energetic equilibrium after 3 million configurations. For evaluation of structural data, especially the radial distribution functions (RDFs), a further 3 million configurations were sampled.

MC simulations with pair potential including the three-body corrections

Under the same conditions as in 2.1(a) MC simulations including the three-body correction terms were carried out for one M(III) and 499 water molecules, water-water interactions being treated again by CF2 potential [45]. Within the cut off limit of $6.0 \AA$ around the metal ion, the three body correction function was applied, as at large M(III)-water distances these terms vanish according to the ab initio results. After randomly generating an initial configuration, the systems reached equilibrium after 3 million configurations. To evaluate radial distribution functions and other structural data, another 3 million configurations were sampled.

\section{RESULTS AND DISCUSSION}

Simulations with only $\mathrm{M}(\mathrm{III})-\mathrm{H}_{2} \mathrm{O}$ pair potential

Results obtained from simulations with only pair-potential are show in Figures 3-5 for Fe(III) and in Figures 6-8 for Co(III) ion. The simulations with only pair potential resulted in a rough overestimation of coordination numbers, namely 8 for both $\mathrm{Fe}$ (III) and $\mathrm{Co}(\mathrm{III})$ ions in water. The M(III)-O RDFs show small peaks that are known to be an artifact of simulations with only pair potentials [49]. The O-M(III)-O angular distributions show unrealistic orientations as a result of the large number of water molecules located in the first hydration shell. It is obvious, therefore, that the pair potential is inadequate and at least 3-body corrections are mandatory to correctly describe the hydration structure of these ions.

Simulations including three-body corrections for $\mathrm{M}(\mathrm{III})-\left(\mathrm{H}_{2} \mathrm{O}\right)_{2}$

$\mathrm{Fe}(\mathrm{III})-\mathrm{H}_{2} \mathrm{O}$

The Fe(III)-O and Fe(III)-H RDFs and their running integration numbers are displayed in Figure 3. The first hydration shell of Fe(III) is represented by a sharp Fe(III)-O peak at $2.07 \AA$. The first hydration shell is well separated from the second one that appears between 3.70 and $4.90 \AA$ (maximum at $4.18 \AA$ ). In the Fe(III)-O RDFs, a third diffuse peak is observed between 5.20 and $6.80 \AA$ which could either termed a third hydration shell or strong ordering effects extended on bulk water molecules by the hydrated Fe(III) ion.

The Fe(III)-H RDF confirms a strictly dipole oriented arrangement of the first-shell water ligands. Some characteristic values for $\mathrm{Fe}(\mathrm{III})-\mathrm{O}$ and $\mathrm{Fe}(\mathrm{III})-\mathrm{H}$ radial distribution functions are listed and compared with results obtained from experimental works and other simulations investigations in Table 2. 


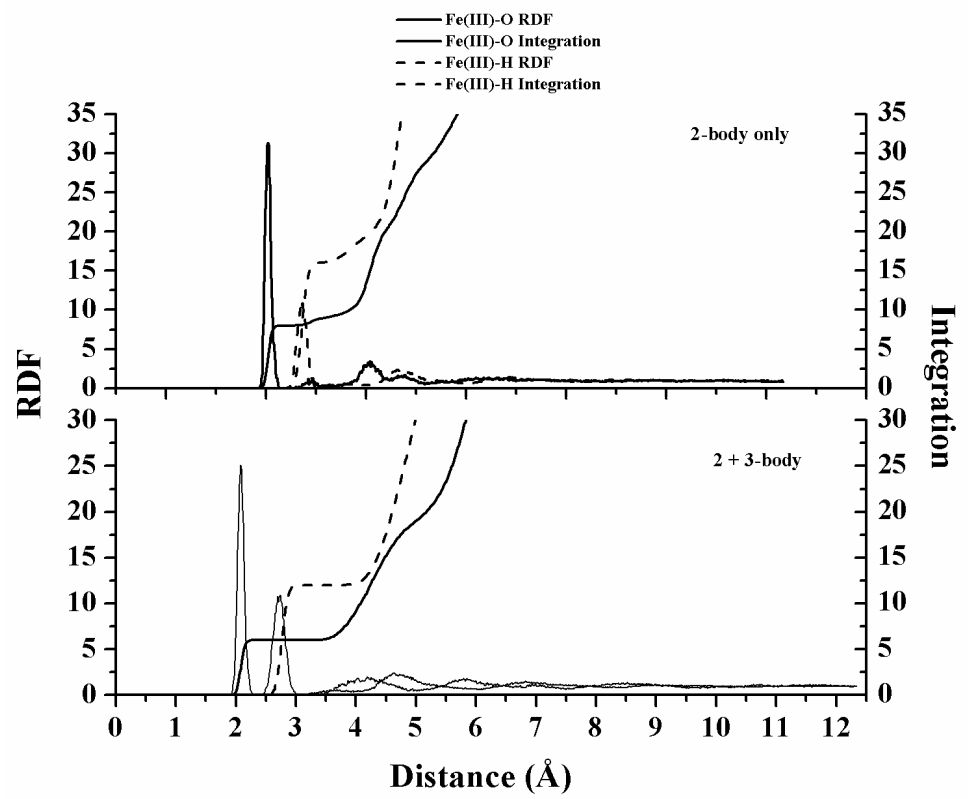

Figure 3. $\mathrm{Fe}(\mathrm{III})-\mathrm{O}$ and $\mathrm{Fe}(\mathrm{III})-\mathrm{H}$ radial distribution functions and their running integration numbers.

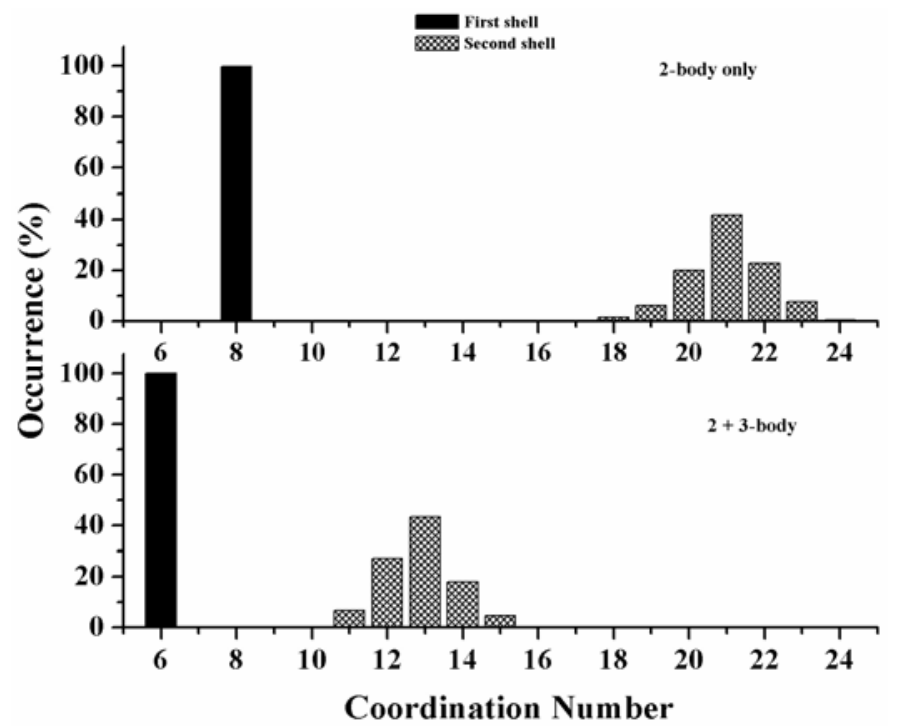

Figure 4. First and second-shell coordination number distribution of hydrated Fe(III).

The first hydration shell contains $100 \% 6$ water molecules (Figure 4). The mean coordination number for the second hydration shell is 13 , implying that some first shell water molecules interact with about 2.3 water molecules in the second shell. This shows that ligand orientation and binding is mainly determined by hydrogen bonding. 
Table 2. Comparison of hydration structure parameters for Fe(III).

\begin{tabular}{|c|c|c|c|c|c|c|c|c|}
\hline System & $\alpha-\beta$ & $\mathrm{N}^{\mathrm{a} / \text { conc }}$ & $r_{1}^{b}$ & $n_{\mathrm{I}}^{\mathrm{c}}$ & $R_{2}{ }^{\mathrm{b}}$ & $n_{2}{ }^{\mathrm{c}}$ & Method & Ref. \\
\hline & $\mathrm{FeO}$ & & 2.07 & 6 & 4.18 & 13 & & This work \\
\hline $\mathrm{Fe}(\mathrm{III})$ & $\mathrm{FeH}$ & 499 & 2.77 & 12 & 4.69 & 48 & $\mathrm{MC}$ & \\
\hline $\mathrm{Fe}\left(\mathrm{ClO}_{4}\right)_{3}$ & $\mathrm{FeO}$ & $1.50 \mathrm{M}$ & 2.00 & 6 & 4.181 & & XRD & 49 \\
\hline $\mathrm{Fe}(\mathrm{NO})_{3}$ & $\mathrm{FeO}$ & $1.52 \mathrm{M}$ & $2.01(2)$ & $6.0(3)$ & & & ND & 50 \\
\hline \multirow[t]{2}{*}{$\mathrm{Fe}(\mathrm{III})$} & $\mathrm{FeO}$ & 216 & 1.98 & 6 & & & $\mathrm{MD}^{\mathrm{d}}$ & 51 \\
\hline & $\mathrm{FeO}$ & & 1.975 & 6 & & & & \\
\hline \multirow[t]{2}{*}{$\mathrm{Fe}(\mathrm{III})$} & $\mathrm{FeH}$ & 125 & 2.675 & & & & $\mathrm{MD}^{\mathrm{e}}$ & 52 \\
\hline & $\mathrm{FeO}$ & & 2.05 & 6 & 4.17 & & & \\
\hline $\mathrm{Fe}(\mathrm{III})$ & $\mathrm{FeH}$ & 216 & 2.74 & & & & $\mathrm{MD}^{\mathrm{f}}$ & 53 \\
\hline $\mathrm{Fe}(\mathrm{III})$ & $\mathrm{FeO}$ & 499 & 2.05 & 6 & 4.30 & 15.1 & $\mathrm{MD}^{\mathrm{g}}$ & $44 a$ \\
\hline$\left[\mathrm{Fe}\left(\mathrm{H}_{2} \mathrm{O}\right)_{6}\right]^{3+}$ & $\mathrm{FeO}$ & & 1.85 & 6 & & & $\mathrm{HF}^{\mathrm{h}}$ & $44 a$ \\
\hline
\end{tabular}

${ }^{\mathrm{a}}$ Number of $\mathrm{H}_{2} \mathrm{O}$ molecules in the simulation box. ${ }^{\mathrm{b}} r_{\mathrm{i}}$ is the distance in $\AA$ of the $i^{\text {th }}$ maximum of the RDF. ${ }^{\mathrm{c}} n_{\mathrm{i}}$ is the average hydration number integrated up $r_{\mathrm{mi}}$ of the $i^{\text {th }}$ shell. ${ }^{\mathrm{d}}$ Empirical potential for ion-water interaction and flexible SPC water model. ${ }^{e}$ Flexible SPC water model and empirical ion-water potential. ${ }^{\mathrm{f}}$ Empirical potential. ${ }^{\mathrm{g}} 2+3$ body potential for ion-water interaction. ${ }^{\mathrm{h}}$ Hartee-Fock.

The probability of finding the O-Fe(III)-O angle $(\theta)$ in the first hydration shell, the first-shell angular distribution function, is shown in Figure 5 as a function of 1-cos $\theta$. Two well-defined peaks are observed at the peak maxima of $90^{\circ}$ and $180^{\circ}$ suggesting an octahedral complex. These results indicate that the hydration geometry around Fe(III) ion is on average a 6coordinate octahedral in agreement with experimental results, Table 2.

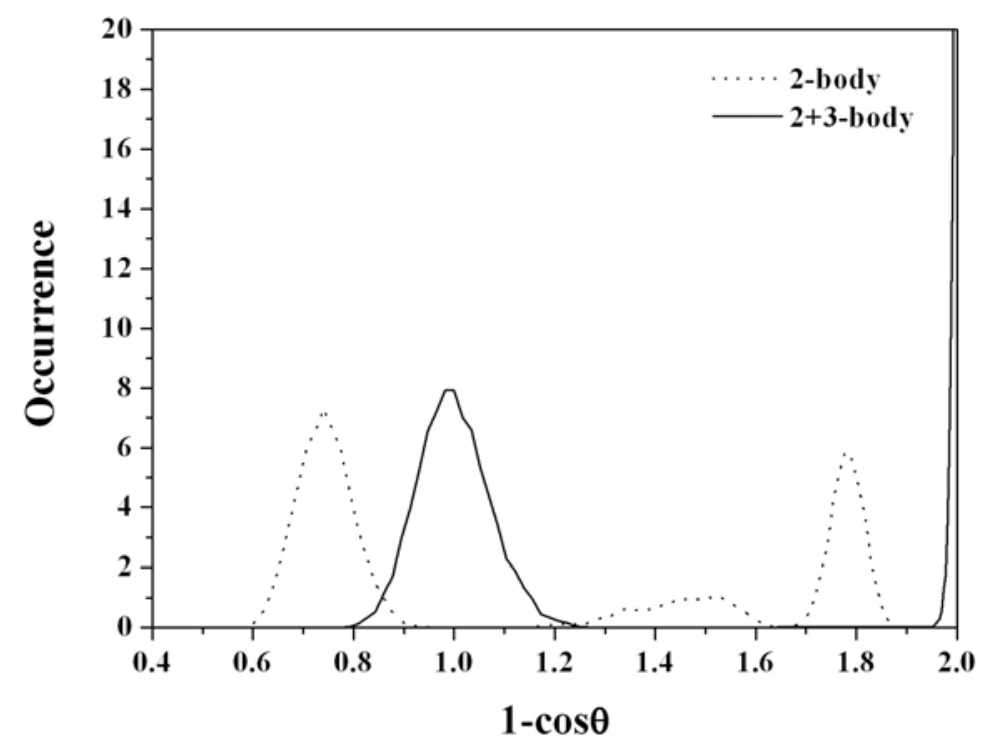

Figure 5. Probability distribution of the $\mathrm{O}-\mathrm{Fe}(\mathrm{III})-\mathrm{O}$ angle $(\theta)$ in the first hydration shell of $\mathrm{Fe}(\mathrm{III})$ ion.

$\mathrm{Co}(\mathrm{III})-\mathrm{H}_{2} \mathrm{O}$

In Figure 6, the RDFs for $\mathrm{Co}(\mathrm{III})-\mathrm{O}$ and $\mathrm{Co}(\mathrm{III})-\mathrm{H}$ and their running integration numbers are displayed. The first $\mathrm{Co}(\mathrm{III})-\mathrm{O}$ peak corresponding to the first hydration shell is centered at 2.00 
$\AA$. This value doesn't differ much from the value obtained using the more sophisticated and extremely time-consuming simulation method, quantum mechanical/molecular mechanical molecular dynamics simulation (QM/MM-MD), Table 3. The fact that the Co(III)-RDF becomes zero after its first peak and almost zero for more than $1 \AA$ suggests that the first hydration shell is tightly bound and that ligand exchange with the second shell should be rather marginal. The second hydration shell is centered at $3.95 \AA$. The $\mathrm{Co}(\mathrm{III})-\mathrm{H}$ RDF confirms again the dipole oriented arrangements of the first-shell ligands. The characteristic values for $\mathrm{Co}(\mathrm{III})-\mathrm{O}$ and $\mathrm{Co}(\mathrm{III})-\mathrm{H}$ radial distribution functions are listed in Table 3.

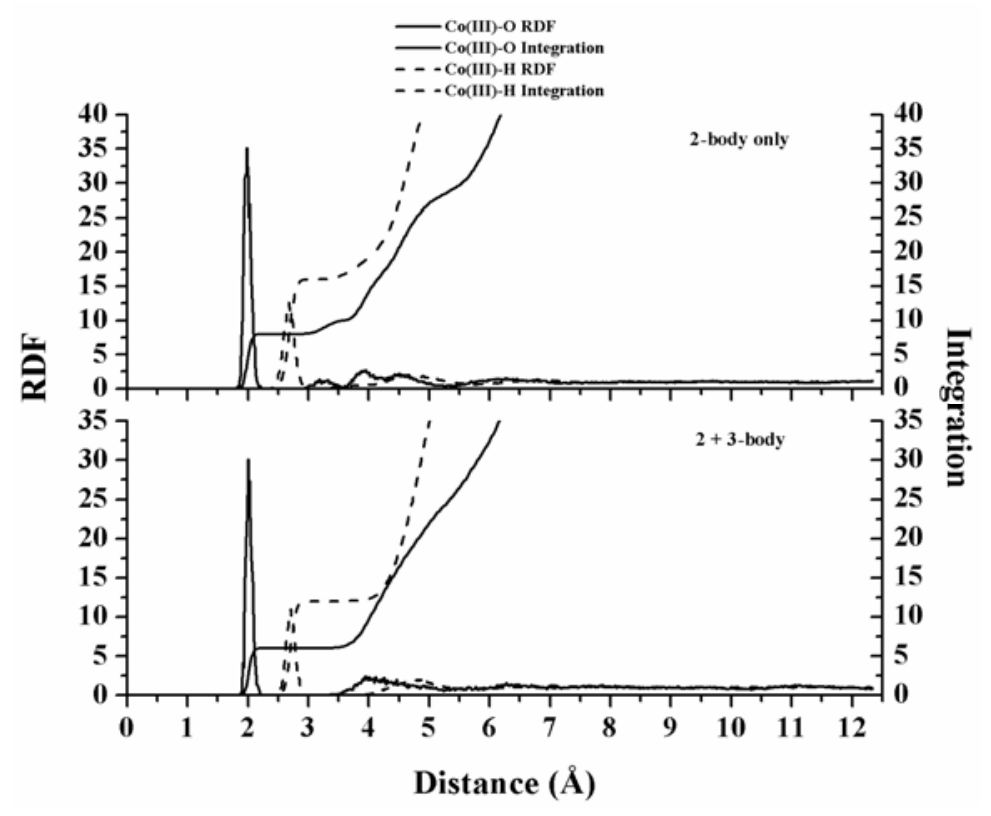

Figure 6. $\mathrm{Co}(\mathrm{III})-\mathrm{O}$ and $\mathrm{Co}(\mathrm{III})-\mathrm{H}$ radial distribution functions and their running integration numbers.

In Figure 7, the percentage distribution of coordination numbers $(\mathrm{CN})$ in the first and second shells is shown for hydrated $\mathrm{Co}(\mathrm{III})$ ion. The first hydration shell $\mathrm{CN}$ is exclusively 6 . In the second hydration shell an average of 18 water molecules are, that means every first shell water molecule interacts with 3 water molecules. This shows that ligand orientation and binding is not entirely determined by hydrogen bonding.

The probability of finding the O-Co(III)-O angle $(\theta)$ in the first hydration shell, the firstshell angular distribution function, is shown in Figure 8 as a function of 1-cos $\theta$. The angular distribution for the $\left[\mathrm{Co}\left(\mathrm{H}_{2} \mathrm{O}\right)_{6}\right]^{3+}$ reveals an octahedral geometry by a well-pronounced peak at $90^{\circ}$ and at $180^{\circ}$. This indicate again that the hydration geometry around $\mathrm{Co}(\mathrm{III})$ ion is on average a 6-coordinate octahedral.

Furthermore, in this study the geometry of $\left[\mathrm{Co}\left(\mathrm{H}_{2} \mathrm{O}\right)_{6}\right]^{3+}$ was optimized at HF level of theory using the same basis sets used to construct the pair potential and three-body correction terms for $\mathrm{Co}(\mathrm{III})-\mathrm{H}_{2} \mathrm{O}[44 \mathrm{~b}]$ and the result is shown in Table 3. The prediction of the longer distance for $\mathrm{Co}$ (III)-O by the $\mathrm{MC}$ simulation than the value observed from the optimized geometry can be understood from the ligand-ligand repulsion. 


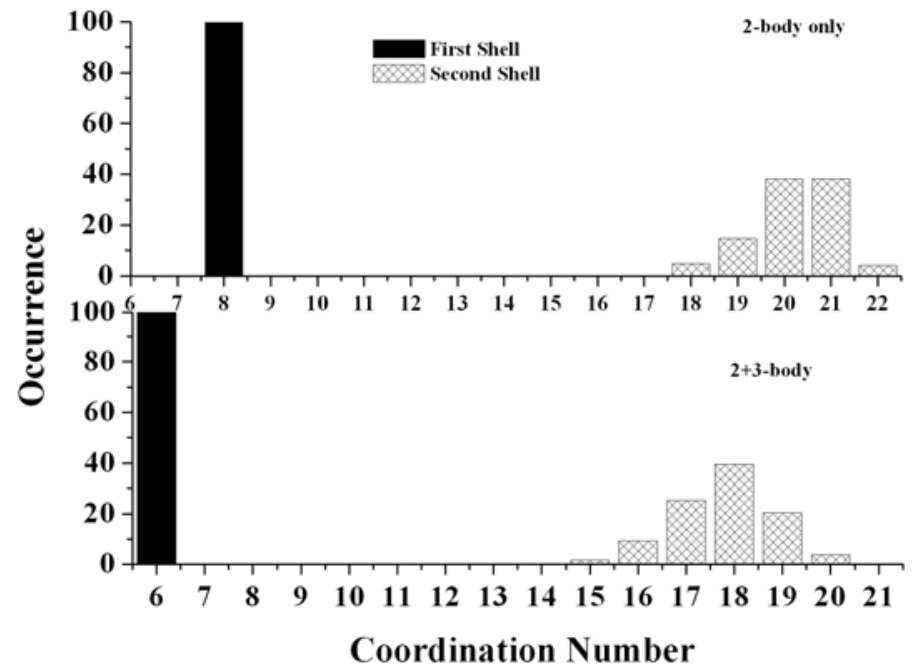

Figure 7. First and second-shell coordination number distribution of hydrated Co(III).

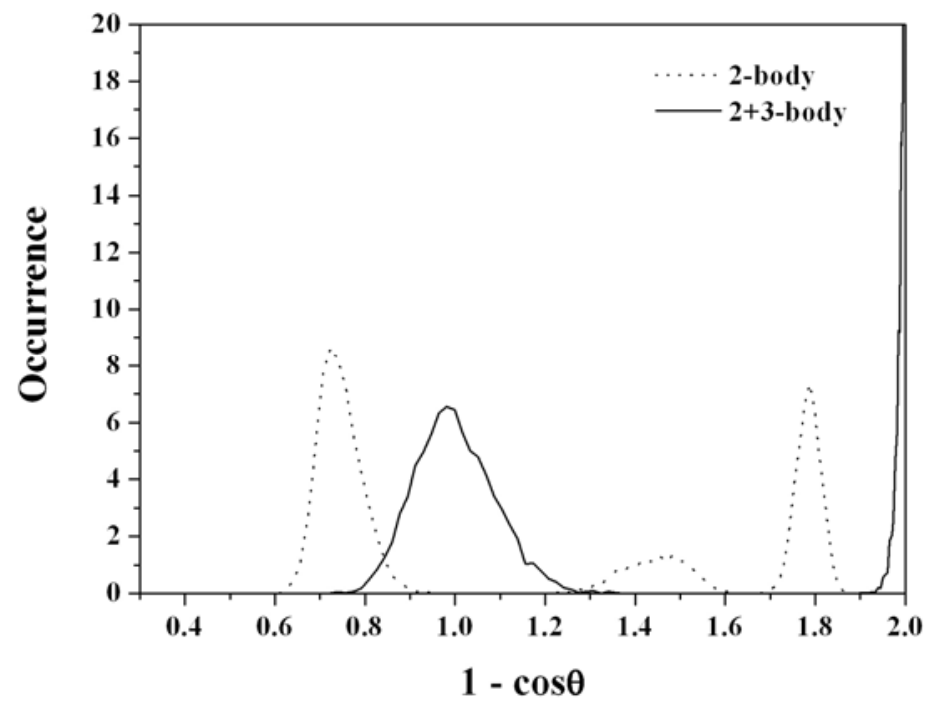

Figure 8. Probability distribution of the $\mathrm{O}-\mathrm{Co}(\mathrm{III})-\mathrm{O}$ angle $(\theta)$ in the first hydration shell of Co(III) ion. 
Table 3. Characteristic values of the radial distribution functions, $\left.g_{\alpha \beta} r\right)$, for the Co(III) in water determined by molecular simulation methods.

\begin{tabular}{|lcccccccc|}
\hline System & $\alpha-\beta$ & $\mathrm{N}^{\mathrm{a}}$ & $r_{1}{ }^{\mathrm{b}}$ & $n_{\mathrm{I}}^{\mathrm{c}}$ & $r_{2}^{\mathrm{b}}$ & $n_{2}{ }^{\mathrm{c}}$ & Method & Ref. \\
\hline $\mathrm{Co}(\mathrm{III})$ & $\mathrm{CoO}$ & 499 & 2.00 & 6 & 3.95 & 18 & & \\
& $\mathrm{CoH}$ & & 2.71 & 12 & 4.87 & 52 & $\mathrm{MC}$ & This work \\
{$\left[\mathrm{Co}\left(\mathrm{H}_{2} \mathrm{O}\right)_{6}\right]^{3+}$} & $\mathrm{CoO}$ & & 1.93 & 6 & - & - & $\mathrm{HF}$ & This work \\
$\mathrm{Co}(\mathrm{III})$ & $\mathrm{CoO}$ & 499 & 2.03 & 6 & 4.43 & 18.8 & $\mathrm{MD}$ & $44 \mathrm{~b}$ \\
$\mathrm{Co}(\mathrm{III})$ & $\mathrm{CoO}$ & 499 & 1.97 & 6 & 4.28 & 15.2 & $\mathrm{QM} / \mathrm{MM}-\mathrm{MD}^{\mathrm{d}}$ & $44 \mathrm{c}$ \\
\hline
\end{tabular}

${ }^{a}$ Number of $\mathrm{H}_{2} \mathrm{O}$ molecules in the simulation box. ${ }^{\mathrm{b}} r_{\mathrm{i}}$ is the distances in $\AA$ of the $i^{\text {th }}$ maximum. ${ }^{\mathrm{c}} n_{\mathrm{i}}$ is the average coordination number obtained by integration of RDF for the $i^{\text {th }}$ coordination shell. ${ }^{\mathrm{d}} 2+3$ body potential for ion-water interaction.

\section{CONCLUSION}

From this study, the most stable structures of the hydrated $\mathrm{Co}(\mathrm{III})$ and $\mathrm{Fe}(\mathrm{III})$ ions in aqueous solution are $\left[\mathrm{Co}\left(\mathrm{H}_{2} \mathrm{O}\right)_{6}\right]^{3+}$ and $\left[\mathrm{Fe}\left(\mathrm{H}_{2} \mathrm{O}\right)_{6}\right]^{3+}$, respectively at $\mathrm{Co}(\mathrm{III})-\mathrm{O}_{1}$ and $\mathrm{Fe}(\mathrm{III})-\mathrm{O}_{1}$ bond distances of 2.07 and $2.00 \AA$, respectively. In addition, a structurally well-defined second hydration coordination shells around the $\mathrm{Co}(\mathrm{III})$ and $\mathrm{Fe}(\mathrm{III})$ ions at $\mathrm{Co}(\mathrm{III})-\mathrm{O}_{2}$ and $\mathrm{Fe}(\mathrm{III})-\mathrm{O}_{2}$ bond distances of 4.18 and $3.95 \AA$, respectively were obtained. The well-defined second hydration coordination shells are formed because of the strong hydrogen bond due to the polarization of the first hydration shell water molecules. The agreement of the structural properties obtained with experimental investigations shows that the inclusion of three-body correction terms represents a proper approach to calculate the hydration of these ions and furthermore to study structural properties of other highly charged metal ions.

Although the low stability of $\mathrm{Co}(\mathrm{III})$ in aqueous solution might rise the question of the usefulness of a theoretical treatment, it should be emphasized here that structural data are essential to understand fundamental processes in solution such as electron transfer reactions. Structural reorganization in a reduction-oxidation reaction for example plays an important role for the overall reaction, and thus hydration structures need to be known in detail $[54,55]$. For this reason computer simulation can be considered as a valid method for the study of ions in solution which are accessible only with great difficulties and limitations to experimental investigations. Hence, computer simulation is an indispensable tool for coordination chemistry.

\section{REFERENCES}

1. Walrafen, G.E. J. Chem. Phys. 1966, 44, 1546.

2. Michaelien, K.H.; Moskovits, M. Nature (London) 1978, 273, 135.

3. Amis, E.S.; Hinton, J.F. Solvent Effects on Chemical Phenomena, Academic: New York, 1973.

4. Enderby, J.E.; Neilson, G.W. Rep. Prog. Phys. 1981, 44, 593.

5. Conway, B.E. Ionic Hydration in Chemistry and Physics, Elsevier: Amsterdam, 1981.

6. Ozutsumi, K.; Koide, M.; Suzuki, H.; Ishiguro, S. J. Phys. Chem. 1993, 97, 500.

7. Neilson, G.W.; Broadbent, R.D.; Howell, I.; Tromp, R.H. J. Chem. Soc., Faraday Trans. 1993, 89, 2927.

8. Ohtaki, H.; Radnai, T. Chem. Rev. 1993, 93, 1157.

9. Cotton, F.A.; Daniels, L.M.; Murillo, C.A.; Quesada, J.F. Inorg. Chem. 1993, 32, 4861.

10. Aizawa, S.; Matsuda, K.; Tajima, T.; Maeda, M.; Sugata, T.; Funahashi, S. Inorg. Chem. 1995, 34, 2042.

11. Rudolph, W.; Brooker, M.H.; Pye, C.C. J. Phys. Chem. 1995, 99, 3793. 
12. Imey, R.W.; Madden, P.A.; McDonald, I.R. J. Phys. Chem. 1983, 87, 5071.

13. Chandrasekhar, J.; Spellmeyer, D.C.; Jorgensen, W.L. J. Am. Chem. Soc. 1984, 106, 903.

14. Kowall, T.; Foglia, F.; Helm, L.; Merbach, A.E. J. Am. Chem. Soc. 1995, 117, 3790.

15. Li, S.H.; Rasaiah, J.C. J. Phys. Chem. 1996, 100, 1420.

16. Kerdcharoen, T.; Liedl, K.R.; Rode, B.M. Chem. Phys. 1996, 211, 313.

17. Marx, D.; Sprik, M.; Parrinello, M. Chem. Phys. Lett. 1997, 273, 360.

18. Marini, G.W.; Texler, N.R.; Rode, B.M. J. Phys. Chem. 1996, 100, 6808.

19. Texler, N.R.; Rode, B.M. J. Chem. Phys. 1995, 99, 15714.

20. Pranowo, H.D.; Rode, B.M. J. Phys. Chem. A 1999, 103, 4298.

21. Marini, G.W.; Liedl, K.R.; Rode, B.M. J. Phys. Chem. A 1999, 103, 11387.

22. Martínez, J.M.; Hernández-Cobos, J.; Saint-Martin, H.; Pappalardo, R.R.; Sánchez Marcos, E. J. Chem. Phys. 2000, 112, 2339.

23. Iglesias-Yagüe, J.; Mohammed, A.M.; Loeffler, H.; Rode, B.M. J. Phys. Chem. A 2001, 105, 7646.

24. Howell, I.; Neilson, G.W. J. Phys.: Condens. Matter 1996, 8, 4455.

25. Stone, J.A. The Theory of Intermolecular Forces, Clarendon Press: Oxford; 1996.

26. (a) Clementi, E.; Corongiu, G.; Jönnson, B.; Romano, S. J. Chem. Phys. 1980, 72, 260. (b) Migliore, M.; Corongiu, G.; Clementi, E.; Lie, G.C. J. Chem. Phys. 1988, 88, 7766.

27. Elrod, N.J.; Berendsen, H.J.C.; Grigera, J.R.; Straatsma, T.P. J. Chem. Phys. 1987, 91, 6269.

28. Elrod, N.J.; Saykally, R.J. Chem. Rev. 1994, 94, 1975.

29. (a) Rode, B.M.; Islam, S.M. Z. Naturforsch. 1991, A46, 357. (b) Yongyai, Y.; Kokpol, S.; Rode, B.M. Chem. Phys. 1991, 156, 403.

30. Mohammed, A.M. Bull. Chem. Soc. Ethiop. 2003, 17, 199.

31. Neilson, G.W.; Enderby, J.E. in Water. A Comprehensive Treatise, Vol. 6, Franks, F. (Ed.), Plenum Press: New York; 1979.

32. Lee, S.H.; Rasaiah, J.C. J. Chem. Phys. 1994, 101, 6964.

33. Obst, S.; Bradaczek, J. Phys. Chem. 1996, 100, 15677.

34. Forester, T.R.; Smith, W.; Clarke, J.H.R. J. Phys. Chem. 1995, 99, 14418.

35. Pranowo, H.D.; Bambang-Setiaji, A.H.; Rode, B.M. J. Phys. Chem. A 1999, 103, 11115.

36. Tongraar, A.; Liedl, K.R.; Rode, B.M. J. Phys. Chem. A 1997, 101, 6299.

37. Cordeiro, M.N.D.S.; Ignaczak, A.; Gomes, A.N.F. Chem. Phys. 1993, $176,97$.

38. (a) Beattie, J.K.; Best, S.P.; Skelton, B.W.; White, A.H. J. Chem. Soc., Dalton Trans. 1981, 2105. (b) Best, S.P.; Forsyth, J.B.; Tregenna-Piggott, P.L. J. Chem. Soc., Dalton Trans. 1993, 2711.

39. Figgis, B.N.; Lewis, J. Prog. Inorg. Chem. 1964, 6, 37.

40. Swann, S.; Xanthakos, T.S. J. Am. Chem. Soc. 1931, 53, 400.

41. (a) Sylva, R.N. Rev. Pure Appl. Chem. 1972, 22, 207. (b) Baes, C.J. Jr.; Mesmer, R.E. in The Hydrolysis of Cations, Wiley-Interscience: New York; 1976. (c) Flymm, C.M. Jr. Chem. Rev. 1984, 84, 31. (d) Fatemi, S.J.A.; Kedir, F.A.A.; Williamson, D.J.; Moore, G.R. $A d v$. Inorg. Chem. 1991, 26, 409. (e) Frandel, R.B.; Blakemore, R.P. (Eds.); Iron Biominerals, Plenum Press: New York; 1991. (f) Crichton, R.R. Inorganic Biochemistry of Iron Metabolism, Ellis Horwood: New York; 1991.

42. (a) Herdman, G.J.; Neilson, G.W. J. Phys.: Condens. Matter 1992, 4, 627. (b) Magini, M. Inorg. Nucl. Chem. 1978, 40, 43. (c) Magini, M.; Caminiti, R. Inorg. Nucl. Chem. 1977, 39, 91. (d) Magini, M.; Saltelli, A.; Caminiti, R. Inorg. Chem. 1981, 20, 3564. (e) Sham, T.J.; Hastings B.K.; Perleman, M.L. Chem. Phys. Lett. 1981, 83, 391. (f) Herdman, G.J.; Neilson, G.W. J. Phys. Condens. Matter 1992, 4, 649. (g) Ohtaki, H.; Yamaguchi, T.; Maeda, M. Bull. Chem. Soc. Japan 1976, 49, 701. (h) Kalman, E.; Radnai, T.; Palinkas, G.; Hajdu, F.; Vertes, A. Electrochim. Acta 1988, 33, 1223.

43. (a) Guárdia, E.; Padró, J.A. Chem. Phys. 1990, 144, 353. (b) Curtiss, L.A.; Halley, J.W.; 
Hautman, J.; Rahman, A. J. Chem. Phys. 1987, 86, 2319. (c) Rustad, J.R.; Hay, B.P.; Halley, J.W. J. Chem. Phys. 1995, 102, 427. (d) Kneifel, G.C.; Friedman, H.L.; Newton, M.D.Z. Naturforsh. 1989, A44, 385.

44. (a) Remsungnen, T.; Rode, B.M. Chem. Phys. Lett. 2004, 385, 491. (b) Kritayakornupong, C; Yague, J.I.; Rode, B.M. J. Phys. Chem. A 2002, 106, 10584. (c) Kritayakornupong, C; Plankensteiner, K.; Rode, B.M. J. Chem. Phys. 2003, 119, 6068.

45. Jancsó, G.; Heinzinger, K.; Bopp. P. Z. Naturforsch. A 1985, 40, 1235.

46. Matsuoka, O.; Clementi, E.; Yoshimine, M. J. Phys. Chem. 1976, 79, 1351.

47. Rode, B.M. J. Phys. Chem. 1992, 96, 4170.

48. Metropolis, N.; Rosenbluth, A.W.; Teller, A.H.; Teller, E. J. Chem. Phys. 1953, 21, 1087.

49. (a) Hannongbua, S. J. Chem. Phys. 1997, 106, 6076. (b) Hannongbua, S.; Rode, B.M. Chem. Phys. 1992, 162, 257.

50. Magini, M. Inorg. Nucl. Chem. 1978, 40, 43.

51. Herdman, G.J.; Neilson, G.W. J. Phys.: Condens. Matter 1992, 4, 627.

52. Curtiss, L.A.; Halley, J.W.; Hautman, J.; Rahman, A. J. Chem. Phys. 1987, 86, 2319.

53. Guárdia, E.; Padró, J.A. Chem. Phys. 1990, 144, 353.

54. Rustad, J.R.; Hay, B.P.; Halley, J.W. J. Chem. Phys. 1995, 102, 427.

55. Sutin, N.; Marcus, R.A., Biochem. Biophys. Acta 1983, 81, 265.

56. Rotzinger, F. J. Chem. Soc., Dalton Trans. 2002, 719. 